\title{
Salivary progesterone and estriol among pregnant women treated with 17- $\alpha$-hydroxyprogesterone caproate or placebo
}

\author{
Mark A. Klebanoff, MD, MPH, Paul J. Meis, MD, Mitchell P. Dombrowski, MD, Yuan Zhao, \\ MS, Atef H. Moawad, MD, Allison Northen, RN, Baha M. Sibai, MD, Jay D. lams, MD, Michael \\ W. Varner, MD, Steve N. Caritis, MD, Mary J. O'Sullivan, MD, Kenneth J. Leveno, MD, \\ Menachem Miodovnik, MD, Deborah Conway, MD, Ronald J. Wapner, MD, Marshall \\ Carpenter, MD, Brian M. Mercer, MD, Susan M. Ramin, MD, John M. Thorp, MD, Alan M. \\ Peaceman, MD, and National Institute of Child Health and Human Development Maternal- \\ Fetal Medicine Units Network \\ National Institute of Child Health and Human Development, Bethesda, MD (Dr Klebanoff); George \\ Washington University Biostatistics Center, Washington, DC (Ms Zhao); and the Departments of \\ Obstetrics and Gynecology, Wake Forest University, Winston-Salem, NC (Dr Meis); Wayne State \\ University, Detroit, MI (Dr Dombrowski); University of Chicago, Chicago, IL (Dr Moawad); University \\ of Alabama at Birmingham, Birmingham, AL (Ms Northen); University of Cincinnati, Cincinnati, $\mathrm{OH}$, \\ and University of Tennessee, Memphis, TN (Dr Sibai); Ohio State University, Columbus, $\mathrm{OH}$ (Dr \\ lams); University of Utah, Salt Lake City, UT (Dr Varner); University of Pittsburgh, Pittsburgh, PA \\ (Dr Caritis); University of Miami, Miami, FL (Dr O'Sullivan); University of Texas Southwestern \\ Medical Center, Dallas, TX (Dr Leveno); Columbia University, New York, NY, and Washington \\ Hospital Center, Washington, DC (Dr Miodovnik); University of Texas at San Antonio, San Antonio, \\ TX (Dr Conway); Drexel University, Philadelphia, PA, and Columbia University, New York, NY (Dr \\ Wapner); Brown University, Providence, RI (Dr Carpenter); Case Western Reserve University, \\ Cleveland, $\mathrm{OH}$ (Dr Mercer); University of Texas at Houston, Houston, TX (Dr Ramin); University of \\ North Carolina, Chapel Hill, NC (Dr Thorp); and Northwestern University, Chicago, IL (Dr \\ Peaceman).
}

\section{Abstract}

OBJECTIVE-The objectives of the study was to determine whether salivary progesterone $(\mathrm{P})$ or estriol (E3) concentration at 16-20 weeks' gestation predicts preterm birth or the response to $17 \alpha-$ hydroxyprogesterone caproate (17OHPC) and whether 17OHPC treatment affected the trajectory of salivary $\mathrm{P}$ and $\mathrm{E} 3$ as pregnancy progressed.

STUDY DESIGN-This was a secondary analysis of a clinical trial of $17 \mathrm{OHPC}$ to prevent preterm birth. Baseline saliva was assayed for P and E3. Weekly salivary samples were obtained from 40 women who received 17OHPC and 40 who received placebo in a multicenter ran-domized trial of $17 \mathrm{OHPC}$ to prevent recurrent preterm delivery.

RESULTS-Both low and high baseline saliva P and E3 were associated with a slightly increased risk of preterm birth. However, 17OHPC prevented preterm birth comparably, regardless of baseline salivary hormone concentrations. 17OHPC did not alter the trajectory of salivary P over pregnancy, but it significantly blunted the rise in salivary E3 as well as the rise in the E3/P ratio.

(C) 2008 Mosby, Inc. All rights reserved.

Presented in part at the 53rd Annual Scientific Meeting of the Society for Gynecologic Investigation, Toronto, ON, Canada, March 2225, 2006; the 27th Annual Clinical Meeting of the Society for Maternal-Fetal Medicine, San Francisco, CA, Feb. 5-10, 2007; and the 20th Annual Meeting of the Society for Pediatric and Perinatal Epidemiologic Research, Boston, MA, June 18-19, 2007. 
CONCLUSION-17OHPC flattened the trajectory of E3 in the second half of pregnancy, suggesting that the drug influences the fetoplacental unit.

\section{Keywords}

17-alpha-hydroxyprogesterone caproate; longitudinal studies; preterm birth; salivary estriol; salivary progesterone

Progesterone has long been recognized as necessary for pregnancy maintenance, and the role of progesterone withdrawal in the initiation of labor in animal species has been known for decades. ${ }^{1}$ However, the role of progesterone withdrawal, as measured by plasma progesterone concentration or the ratio of progesterone/estrogens, in the initiation of normal labor in humans or other primates is unclear. ${ }^{2-4}$ Nevertheless, there is evidence that functional progesterone withdrawal caused by changes such as reduction in progesterone receptors ${ }^{5}$ or relative increase in the progesterone receptor (PR)-A progesterone receptor isoform, which blocks PR-B isoform-mediated gene transcription ${ }^{6}$ may trigger labor in humans. We are unaware of any study that has assessed the ability of measurement of salivary progesterone, which is representative of the biologically active unbound fraction in plasma or serum, ${ }^{7}$ to predict preterm birth.

In 2 recent randomized clinical trials, injections of 17- $\alpha$-hydroxyprogesteronecaproate $(17 \mathrm{OHPC})^{8}$ or vaginal suppositories containing progesterone ${ }^{9}$ reduced the recurrence or occurrence of preterm birth among high-risk women. Because 17- $\alpha$-hydroxyprogesterone is produced by the normal placenta in amounts greater than the doses administered in these clinical trials ${ }^{10}$ and because normal plasma progesterone concentrations are 9 times higher than those of 17- $\alpha$-hydroxyprogesterone ${ }^{11}$ and greater than the dissociation constant of the progesterone receptor, ${ }^{12}$ the mechanism for this preventive effect is uncertain. If these drugs worked by counteracting mild progesterone deficiency, then one might hypothesize them to be more effective among women with lower salivary progesterone concentrations at the start of treatment or that these drugs would modify the change in progesterone concentrations as pregnancy progressed.

We therefore conducted this secondary analysis of our previously published $17 \mathrm{OHPC}$ trial $^{8}$ to test the hypotheses that the concentration of progesterone in saliva, measured at 16-20 weeks' gestation, can be used to predict which women will deliver at less than 37 weeks' gestation; that women with low salivary progesterone concentration at baseline will be more likely to benefit from 17- $\alpha$-hydroxyprogesterone caproate injections; and that compared with placebo, treatment with 17OHPC will cause a more rapid rise in progesterone concentration as pregnancy progressed.

\section{Materials and Methods}

This is a secondary analysis from Maternal-Fetal Medicine Units Network randomized, doublemasked, placebocontrolled clinical trial of 17- $\alpha$-hydroxyprogesterone caproate to prevent recurrent preterm birth, the methods and results of which have been reported previously. ${ }^{8}$ In summary, the trial enrolled 463 women with at least 1 previous spontaneous preterm delivery and randomized them to receive weekly injections of 17- $\alpha$-hydroxyprogesterone caproate (n $=310)$ or castor oil placebo $(n=153)$ beginning at 16 to $20^{6 / 7}$ weeks' gestation, confirmed by sonography, and continuing until 36 weeks 6 days' gestation. The trial demonstrated a reduction in recurrent preterm birth from $54.9 \%$ in the placebo group to $36.3 \%$ in the treatment group. 
As part of the trial protocol, saliva specimens for estriol and progesterone were collected from the women immediately before receipt of the initial injection and then each week until 36 weeks 6 days, prior to receipt of the weekly injection. All samples were collected between 9 am and 8 Рм and were taken approximately 1 week after receipt of 17OHPC. Women were asked to refrain from eating, drinking, smoking, chewing gum, tooth brushing, or flossing for 1 hour before the visit and to rinse their mouths with water 10 minutes before collecting the sample. The women could also collect the sample at home, following the same procedure. Samples were stored at room temperature for up to 48 hours and then at $-80^{\circ} \mathrm{C}$.

Total salivary estriol was assayed using the SalEst (Adeza Inc, Sunnyvale, CA) enzyme-linked immunosorbent assay test kit, following the manufacturer's instructions. The test sensitivity was $0.19 \mathrm{ng} / \mathrm{mL}$, within and between batch coefficients of variation were generally $10 \%$ or less, and there was negligible cross-reactivity with steroids other than estriol and its conjugates. 13 Total progesterone was assayed with the Salimetrics (Salimetrics LLC, State College, PA) salivary progesterone competitive enzyme immunoassay kit, according to the manufacturer's recommendations. The test sensitivity was $5 \mathrm{pg} / \mathrm{mL}$, and the intra- and interas-say coefficients of variation were both less than $10 \%$. Cross-reactivity with other steroids was negligible. In particular, cross-reactivity with 17- $\alpha$-hydroxyprogesterone was $0.07 \%$. All assays were performed by Adeza, Inc.

Gestational age at birth, in completed weeks, was determined from the sonographicallyconfirmed gestational age at randomization and the time elapsed from randomization to birth; for the analysis of baseline concentrations, preterm $(<37$ completed weeks) birth was the outcome of interest, with delivery at less than 35 and less than 32 weeks as secondary outcomes.

Continuous variables were compared using the Wilcoxon rank-sum test and categorical variables were compared using the $\chi^{2}$ test. When categories were ordered, significance was assessed with the Cochran-Armitage test for trend. ${ }^{14}$ Multiple logistic regression was used to adjust the association between baseline salivary estriol or progesterone and preterm birth for gestational week when the sample was obtained and treatment group. To determine whether the effectiveness of treatment differed according to baseline estriol or progesterone, women were stratified by whether their concentration was low $(<25 \%)$, midrange $(25-75 \%)$, or high $(>75 \%)$, and rate of preterm birth was compared between the treatment and control groups within each stratum in 2-by-3 tables. We used the Breslow-Day test ${ }^{15}$ to determine whether treatment effect differed significantly by baseline salivary steroid concentrations.

The clinical trial included 463 women who contributed 6305 samples for progesterone (462 of whom contributed 6298 samples for estriol). Analyses of baseline hormone levels were restricted to women who provided these samples in sufficient volume (413 women for estriol and 386 for progesterone); those with missing samples did not differ significantly from those with samples available for both assays on any of the characteristics in Table 1 . The analysis to determine whether treatment with 17OHPC modified the normal longitudinal change in salivary hormones was restricted to women who collected a salivary sample in all eligible weeks and whose visits were on schedule (ie, within 5-10 days of each other). There were 157 such women, who were more likely than other women in the trial to be white $(P=.002)$ and older $(P$ for trend $=.007)$. However, there were no significant differences in treatment group, preterm birth in the treated pregnancy, gestational age at the start of treatment, the number of previous spontaneous preterm births, body mass index, years of education, or smoking status.

From among the 157 women with on-schedule visits, we randomly selected 20 women who received 17OHPC and delivered preterm, 20 who received 17OHPC and delivered at term, 20 who received placebo and delivered preterm, and 20 who received placebo and delivered at term; the number was based on available resources rather than a formal sample size estimate. 
These 80 women contributed a total of 1244 saliva samples for the study of estriol and 1158 for progesterone. The longitudinal analysis used mixed models to account for the nonindependence of multiple hormone measures obtained on each woman. To determine whether 17OHPC affected the trajectory of salivary hormones, we modeled the salivary hormone levels as a function of treatment (17OHPC vs placebo), gestational age (as a linear term), and the interaction of treatment and gestational age. Statistical significance of this interaction term would indicate that the trajectory of salivary hormone with advancing gestational age differed between the 17OHPC and placebo groups. The primary study protocol, including collection and analysis of the saliva samples, was approved by the institutional review boards of the clinical sites and the Biostatistical Coordinating Center, and all women provided written informed consent.

\section{Results}

Among the 413 women with baseline samples, 170 (41\%) gave birth to a preterm infant. Because the beneficial effect of 17OHPC was similar, regardless of baseline salivary progesterone or estriol (see below), the treated and placebo groups were combined in the analysis of the association between baseline hormones and preterm birth. The association among various characteristics of the women and salivary hormone concentrations and preterm birth are presented in Table 1. In this high-risk population, only gestational age at specimen collection was statistically significantly associated with salivary estriol $(P<.001)$ and progesterone $(P=.02)$; the levels of both hormones were higher at later gestational ages. Progesterone levels decreased with advancing maternal age, but the association was of borderline statistical significance $(P=.09)$. All other factors in the table were not associated with either hormone measurement (all $P>.20$ ). In addition, as has been previously described, 16 the only characteristic associated with preterm birth in the study pregnancy was the number of previous preterm births. Compared with women with a history of a single preterm birth, those with more than 1 previous preterm birth were at increased risk.

The median baseline salivary progesterone concentration among women who delivered preterm was $488 \mathrm{pg} / \mathrm{mL}$ ( 25 th to the 75 th percentile $319-724$ ), compared with $446 \mathrm{pg} / \mathrm{mL}$ ( 25 th to the 75th percentile 318-619) among women who delivered at term $(P=.08)$. The corresponding values for estriol were $0.40(0.2-0.5) \mathrm{ng} / \mathrm{mL}$ and $0.40 \mathrm{ng} / \mathrm{mL}(0.2-0.5 ; P=.94)$. The association between low, mid, and high salivary concentrations of steroid hormones and preterm birth at different gestational ages is presented in Table 2.

There were tendencies for both high and low values of both salivary progesterone and estriol to be associated with increased occurrence of preterm birth, although only the associations between low salivary estriol and birth at less than 35 and less than 32 weeks' gestation, and high progesterone and birth at less than 35 weeks' gestation were statistically significant. Associations between salivary hormones and spontaneous preterm birth were in the same direction as the associations with total preterm birth but were virtually always of smaller magnitude. Only the association between estriol less than the 25th percentile and spontaneous preterm birth less than 32 weeks was statistically significant (odds ratio, 2.0; 1.02-3.9). Neither high ( $>$ the 75 th percentile) nor low ( $<$ the 25 th percentile) baseline estriol/progesterone ratio was significantly associated with total or spontaneous preterm birth at less than 37 , less than 35 , or less than 32 weeks' gestation.

Adjustment for gestational age at sample collection and treatment assignment had minimal impact on the results, but after adjustment only the odds ratio for estriol less than the 25th percentile and preterm birth less than 32 weeks remained statistically significant. 
The effect of 17- $\alpha$-hydroxyprogesterone caproate to prevent preterm birth, stratified by the baseline salivary concentrations of progesterone and estriol, is presented in Figure 1. The drug reduced the occurrence of preterm birth, regardless of baseline progesterone or estriol, and the reduction afforded did not differ significantly according to the baseline value of either hormone (Breslow-Day $P$ value for interaction $=.77$ for progesterone, .72 for estriol).

In the longitudinal analysis, mean salivary concentrations of progesterone and estriol and the estriol/progesterone ratio by week of gestation as well as their predicted trajectories are presented according to treatment group in Figure 2.

Progesterone concentration increased with gestational age in both groups, but the trajectory of salivary progesterone did not differ between women assigned to $17 \mathrm{OHPC}(56 \mathrm{pg} / \mathrm{L}$ per week; 95\% confidence interval [CI], 45-65) or to placebo (43 pg/L per week; $95 \% \mathrm{CI}, 35-51 ; P$ for interaction $=.38$ ). However, there was a statistically significant difference in the trajectory of the rise in salivary estriol according to treatment group.

Although salivary estriol rose in both groups as pregnancy progressed, the rise in estriol was significantly less among women assigned to receive $17 \mathrm{OHPC}(0.051 \mathrm{ng} / \mathrm{L}$ per week; $95 \% \mathrm{CI}$, $0.038-0.063)$ than to placebo $(0.069 \mathrm{ng} / \mathrm{L}$ per week; $95 \% \mathrm{CI}, 0.057-0.080 ; P$ for interaction $=$. $013)$.

As a result of these changes, the estriol/progesterone ratio differed significantly between the 2 groups as pregnancy progressed. The ratio rose in the placebo group with advancing gestation $\left(3.9 \times 10^{-5} \mathrm{ng} / \mathrm{pg}\right.$ per week; $\left.95 \% \mathrm{CI}, 1.5-6.3\right)$, but in the 17OHPC group, the trajectory was essentially flat $\left(-3.1 \times 10^{-6} \mathrm{ng} / \mathrm{pg}\right.$ per week; $95 \% \mathrm{CI},-1.8$ to +1.2$)$. It was not possible to calculate a $P$ value for the entire treatment course because the statistical model failed to converge. However, the difference in trajectory between the 17OHPC and placebo groups was significant over the first 8 weeks of treatment $(P$ for interaction $=.003)$.

\section{Comment}

Contrary to our hypotheses, we did not find either reduced salivary progesterone or elevated estriol concentration at study entry (16-23 weeks' gestation) to be associated with preterm birth. In fact, we found statistically significant associations between elevated salivary progesterone and increased risk of birth at less than 35 weeks' gestation. We also noted statistically significant associations between reduced salivary estriol and increased risk of birth at less than 35 and 32 weeks' gestation. We also found that the beneficial effect of 17OHPC in reducing preterm birth was not statistically different according to baseline salivary concentrations of either progesterone or estriol. However, we noted that compared with placebo, 17OHPC supplementation blunted the rise in salivary estriol and eliminated the rise in the estriol/progesterone ratio, with advancing gestation.

Although salivary progesterone concentrations are reflective of the biologically active levels of free progesterone in serum, ${ }^{7}$ our failure to find an association between reduced baseline salivary progesterone and preterm birth agrees with reports noting that serial plasma progesterone concentrations did not predict preterm delivery. ${ }^{4}$ Nevertheless, there is evidence that in humans the progesterone withdrawal that triggers normal labor is a functional withdrawal within the uteroplacental unit, caused by local inactivation of progesterone, change in the ratio of receptor isoforms, or other mechanisms. ${ }^{17}$ However, measurements at 16-20 weeks might not be reflective of changes occurring later in pregnancy.

Contrary to our hypothesis, we found that 17OHPC supplementation did not have an impact on the trajectory of salivary progesterone. This is in agreement with Reijnders et al, ${ }^{18}$ who reported that $17 \mathrm{OHPC}$ elevated serum progesterone by $20 \%$, which was not statistically 
significant. However, we found that 17OHPC impacted the trajectory of salivary estriol as pregnancy progressed. This trajectory may be of importance, given that salivary estriol and the estriol/progesterone ratio rise throughout gestation, and that in particular, the estriol/ progesterone ratio rises dramatically immediately before term ${ }^{19}$ and preterm ${ }^{20}$ labor. In addition, 2 consecutively elevated salivary estriol measurements have been strongly associated with impending preterm delivery. ${ }^{21}$

Because estriol derives from dehydroepiandrosterone sulfate (DHEAS) produced by the fetal adrenal and modified by the fetal liver and placenta, rather than the mother, ${ }^{22}$ this raises the possibility that 17OHPC prevents preterm birth by acting on the fetus and placenta. Alternatively 17OHPC might have a direct impact on fetal adrenal function. In normal pregnancy, 17- $\alpha$-hydroxyprogesterone is produced by the placenta from 17- $\alpha$-hydroxy- $\Delta^{5}$ pregnenolone sulfate, a product of the fetal adrenal. The latter is an also intermediary in the production of DHEAS, which itself is ultimately converted to estriol. Placental 17- $\alpha$ hydroxyprogesterone is in turn utilized by the fetal adrenal to produce cortisol. ${ }^{23-25}$

Because $17 \mathrm{OHPC}$ crosses the placenta, ${ }^{26}$ it might prevent preterm birth by providing a downstream intermediary for fetal cortisol production and increasing the fetal adrenal's efficiency in producing cortisol. This in turn would suppress its production of DHEAS and ultimately reduce the placenta's production of estriol. Such a mechanism might explain the finding that $17 \mathrm{OHPC}$ failed to prevent preterm birth in twins, ${ }^{27}$ in which the primary stimulus for labor may be uterine distention, ${ }^{28}$ rather than fetal adrenal activity.

Our study has several limitations. The number of women analyzed was determined by available resources. A formal sample size calculation for a longitudinal analysis would require knowledge of both the between- and within-woman variation in salivary hormones. We were unable to find such data, and therefore, we did not estimate a sample size a priori. We did not obtain biospecimens other than maternal saliva. In particular, we did not have a means to assess local hormone changes in vaginal/cervical fluid or to assess changes in progesterone receptor isoforms in the placenta or fetal membranes. Similarly, we did not obtain maternal serum or plasma. We also did not collect systematic data on cervical status or uterine contractility, so we cannot determine what effect 17OHPC might have had on these organs. Nor did we collect data on the time of day when the saliva was collected. Although there is no reason to suspect systematic differences between 17OHPC and placebotreated women in the time of collection, lack of knowledge of time of sample collection is likely to be a source of random error.

Determining the effect of 17OHPC supplementation on these factors and its potential impact on the fetoplacental unit are promising avenues of further research.

\section{Acknowledgments}

In addition to the authors, other members of the National Institute of Child Health and Human Development MaternalFetal Medicine Units Network are as follows: University of Alabama at Birmingham, D. Rouse, J. Hauth; Brown University, H. Silver, J. Tillinghast; Case Western Reserve University, P. Catalano, C. Milluzzi; University of Chicago, P. Jones, M. Lindheimer; University of Cincinnati, N. Elder, T. Siddiqi; Columbia University, M. D'Alton, V. Pemberton; The George Washington University Biostatistics Center, A. Das, Y. Zhao, S. Leindecker; University of Pittsburgh, M. Cotroneo, K. Lain; University of Miami, C. Alfonso, S. Beydoun; National Institute of Child Health and Human Development, C. Spong, D. McNellis, S. Pagliaro; University of North Carolina, Chapel Hill, K. Dorman, K. Moise; Northwestern University, G. Mallet, M. Socol; Ohio State University, F. Johnson, M. Landon; University of Tennessee, R. Ramsey; University of Texas at San Antonio, O. Langer, S. Nicholson; University of Texas at Houston,M. C. Day, L. Gilstrap; University of Texas Southwestern Medical Center, J. McCampbell, G. Wendel; Vanderbilt University Medical Center, S. Gabbe; Drexel University, M. DiVito, J. Tolosa; University of Utah, M. Belfort, E. Taggart; Wake Forest University, E. MuellerHeubach, M. Swain; and Wayne State University, G. Norman, Y. Sorokin. The saliva assays were conducted by Adeza, Inc. Adeza received a copy of the draft manuscript but had no input into the analysis of the data or the content of the manuscript. 
Supported by Grants HD27860, HD36801, HD27917, HD21414, HD27861, HD27869, HD27905, HD34208, HD34116, HD21410, HD27915, HD34136, HD34210, HD34122, HD40500, HD40544, HD34116, HD40560, and HD40512 from the National Institute of Child Health and Human Development.

\section{REFERENCES}

1. Csapo AI. Progesterone “block.”. Am J Anat 1956;98:273-91. [PubMed: 13326855]

2. Cousins LM, Hobel CJ, Chang RJ, Okada DM, Marshall JR. Serum progesterone and estradiol-17b levels in premature and term labor. Am J Obstet Gynecol 1977;127:612-5. [PubMed: 842587]

3. Johnson JWC, Lee PA, Zachary AS, Calhoun S, Migeon CJ. High-risk prematurity-progestin treatment and steroid studies. Obstet Gynecol 1979;54:412-8. [PubMed: 492618]

4. Block BS, Liggins GC, Creasy RK. Preterm delivery is not predicted by serial plasma estradiol or progesterone concentration measurements. Am J Obstet Gynecol 1984;150:716-22. [PubMed: 6496593]

5. Goldman S, Weiss A, Altmalah I, Shalev E. Progesterone receptor in human decidua and fetal membranes before and after contractions: possible mechanism for functional progesterone withdrawal. Mol Hum Reprod 2005;11:269-77. [PubMed: 15764807]

6. Oh SY, Kim CJ, Park I, et al. Progesterone receptor isoform (A/B) ratio of human fetal membranes increases during term parturition. Am J Obstet Gynecol 2005;193:1156-60. [PubMed: 16157129]

7. Meulenberg PMM, Hofman JA. Salivary progesterone excellently reflects free and total progesterone in plasma during pregnancy. Clin Chem 1983;35:168-72. [PubMed: 2910560]

8. Meis PJ, Klebanoff MA, Thom E, et al. Prevention of recurrent preterm birth by 17 alphahydroxyprogesterone caproate. N Engl J Med 2003;348:2379-85. [PubMed: 12802023]

9. daFonseca EB, Bittar RE, Carvalho MH, Zugaib M. Prophylactic administration of progesterone by vaginal suppository to reduce the incidence of spontaneous preterm birth in women at increased risk: a randomized place-bo-controlled double-blind study. Am J Obstet Gynecol 2003;188:419-24. [PubMed: 12592250]

10. Tulchinsky D, Simmer H. Sources of plasma $17 \alpha$-hydroxyprogesterone in human pregnancy. J Clin Endocrinol Metab 1972;35:799-808. [PubMed: 4634481]

11. Tulchinsky D, Hobel CJ, Yeager E, Marshall JR. Plasma estrone, estriol, progesterone and 17hydroxyprogesterone in human pregnancy. I. Normal pregnancy. Am J Obstet Gynecol 1972;112:1095-100. [PubMed: 5025870]

12. Navarro D, Cabrera JJ, Falc O, et al. Monoclonal antibody characterization of progesterone receptors, estrogen receptors and the stress-responsive protein of $27 \mathrm{kDa}$ (SRP27) in human uterine leiomyoma. J Steroid Biochem 1989;34:491-8. [PubMed: 2626044]

13. Voss HF. Saliva as a fluid for measurement of estriol levels. Am J Obstet Gynecol 1999;180:S22631. [PubMed: 9914623]

14. Armitage, P. Statistical methods in medical research. Third printing. Blackwell Scientific Publications; London: 1971. p. 363-5.

15. Breslow, NE.; Day, NE. Statistical methods in cancer research. The analysis of case-control studies. Vol. 1. International Agency for Research on Cancer; Lyon (France): 1980. p. 142

16. Meis PJ, Klebanoff MA, Dombrowski MP, et al. Does progesterone treatment influence risk factors for recurrent preterm delivery. Obstet Gynecol 2005;106:557-61. [PubMed: 16135587]

17. Brown AG, Leite RS, Strasss JF III. Mechanisms underlying "functional” progesterone withdrawal at parturition. Ann N Y Acad Sci 2004;1034:36-49. [PubMed: 15731298]

18. Reijnders FJL, Thomas CMG, Doesburg WH, Rolland R, Eskes TKAB. Endocrine effects of 17alpha hydroxyprogeterone caproate during early pregnancy: a double-blind clinical trial. BJOG 1988;95:462-8.

19. Darne J, McGarrigle HHG, Lachelin GCL. Saliva oestriol, oestradiol, oestrone and progesterone levels in pregnancy: spontaneous labor at term is preceded by a rise in the saliva oestriol: progesterone ratio. BJOG 1987;94:227-35.

20. Darne J, McGarrigle HHG, Lachelin GCL. Increased salivary oestriol to progesterone ratio before idiopathic preterm delivery: a possible predictor for preterm labor. BMJ 1987;294:270-2. [PubMed: 3101838] 
21. Heine RP, McGregor JA, Goodwin, et al. Serial salivary estriol to detect an increased risk of preterm birth. Obstet Gynecol 2000;96:490-7. [PubMed: 11004346]

22. Goodwin TM. A role for estriol in human labor, term and preterm. Am J Obstet Gynecol 1999;180:S208-13. [PubMed: 9914619]

23. Hobel CJ. Stress and preterm birth. Clin Obstet Gynecol 2004;47:856-80. [PubMed: 15596939]

24. Buster JE. Gestational changes in steroid hormone biosynthesis, secretion, metabolism and action. Clin Perinatol 1983;10:527-52. [PubMed: 6360467]

25. Albrecht ED, Pepe GJ. Source and regulation of $17 \alpha$-hydroxyprogesterone during baboon pregnancy. Biol Reprod 1984;31:471-9. [PubMed: 6487691]

26. Hemauer S, Patrikeeva S, Hankins G, Ahmed M, Nanovskaya T. Human placental transfer of 17hydroxyprogesterone caproate. Am J Obstet Gynecol 2006;195:S58.

27. Rouse DJ, Caritis SN, Peaceman AM, et al. for the NICHD MFMU Network. A trial of 17hydroxyprogesterone caproate to prevent pre-maturity in twins. N Engl J Med 2007;357:454-61. [PubMed: 17671253]

28. Lockwood CJ. Testing for risk of preterm delivery. Clin Lab Med 2003;23:345-60. [PubMed: 12848448] 


\section{PreTEan}

0

$\pi$

6

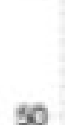

30

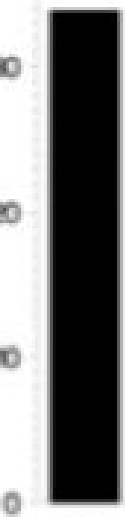

IP PLC

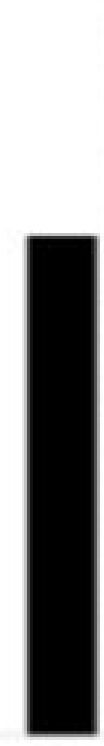

$p 00<25$

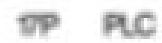

Pog $25-\pi s$

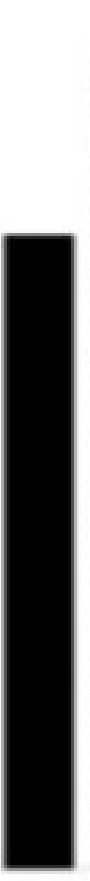

op RC

fog $>$ Fhs

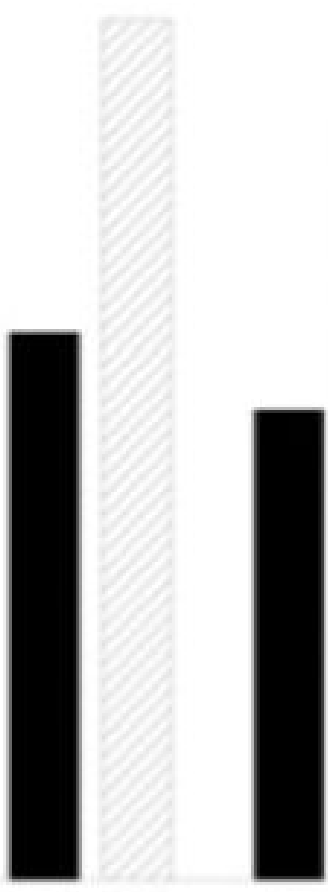

TP PLC

DP PLC

E3 Z $5-$ TSS

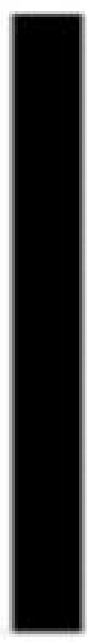

op PLC

Es $>$ TSN

FIGURE 1. Preterm birth by treatment (17P/placebo) and baseline salivary progesterone and estriol percentiles

Klebanoff. Salivary progesterone and estriol among pregnant women treated with 17- $\alpha-$ hydroxyprogesterone caproate or placebo. Am J Obstet Gynecol 2008. 

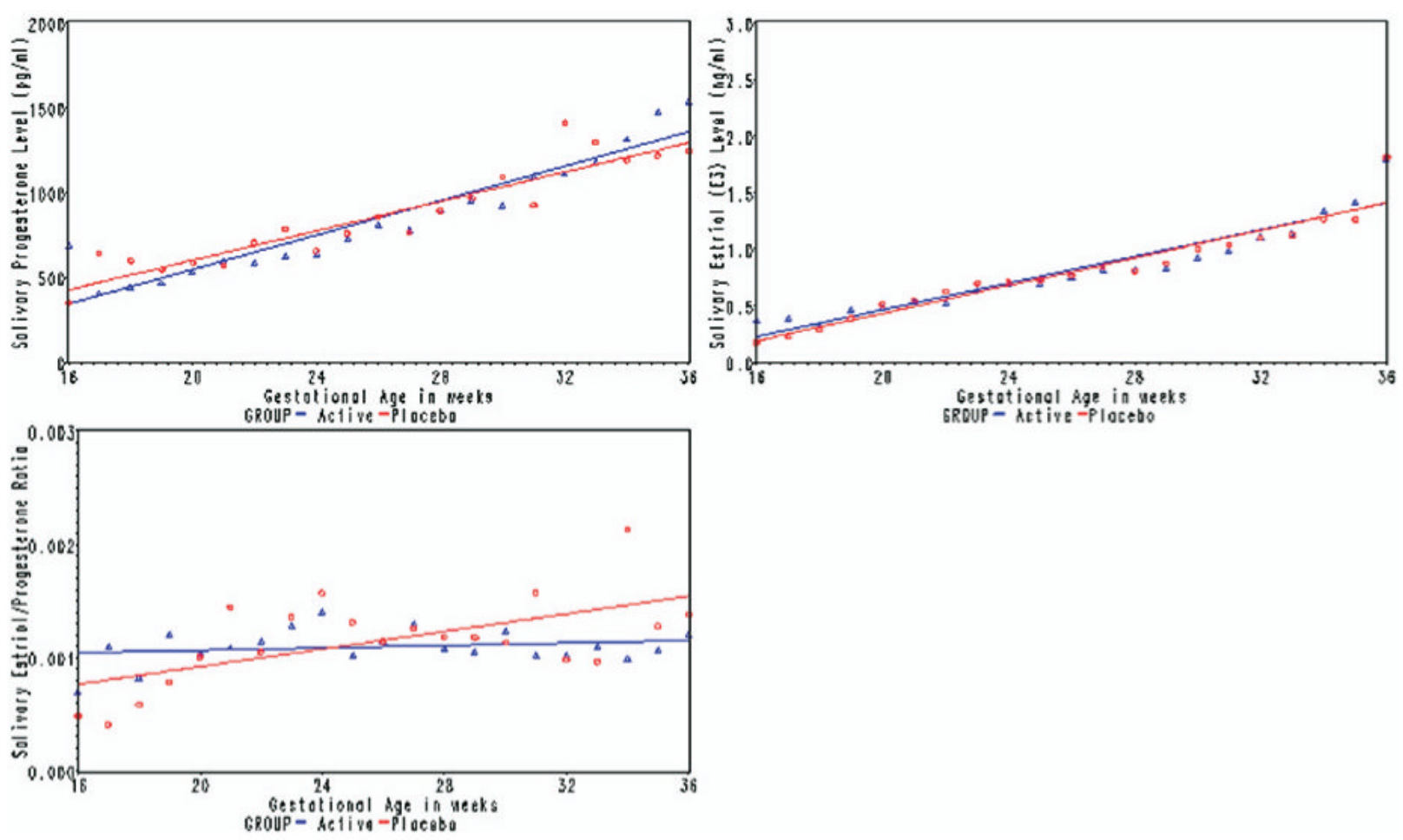

FIGURE 2. Weekly values of salivary progesterone, estriol, and the progesterone/estriol ratio according to treatment group Weekly values of salivary progesterone (A), estriol (B), and the progesterone/estriol ratio (C) according to treatment group. $P$ value for difference in slope between drug- and placebo-treated women $=.38$ for progesterone, .013 for estriol, and .003 for progesterone/estriol ratio.

Klebanoff. Salivary progesterone and estriol among pregnant women treated with 17- $\alpha$ hydroxyprogesterone caproate or placebo. Am J Obstet Gynecol 2008. 


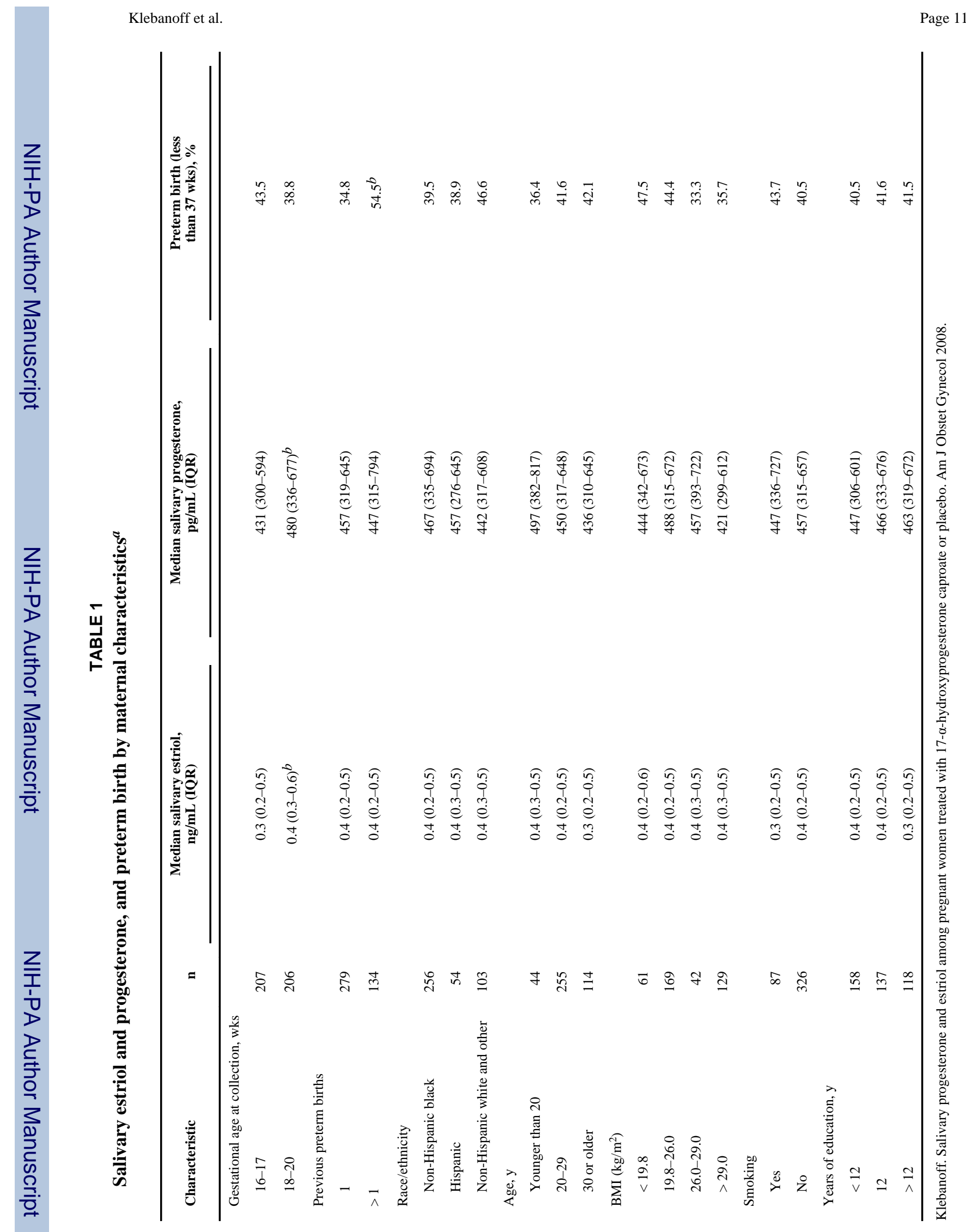

Am J Obstet Gynecol. Author manuscript; available in PMC 2009 December 16. 


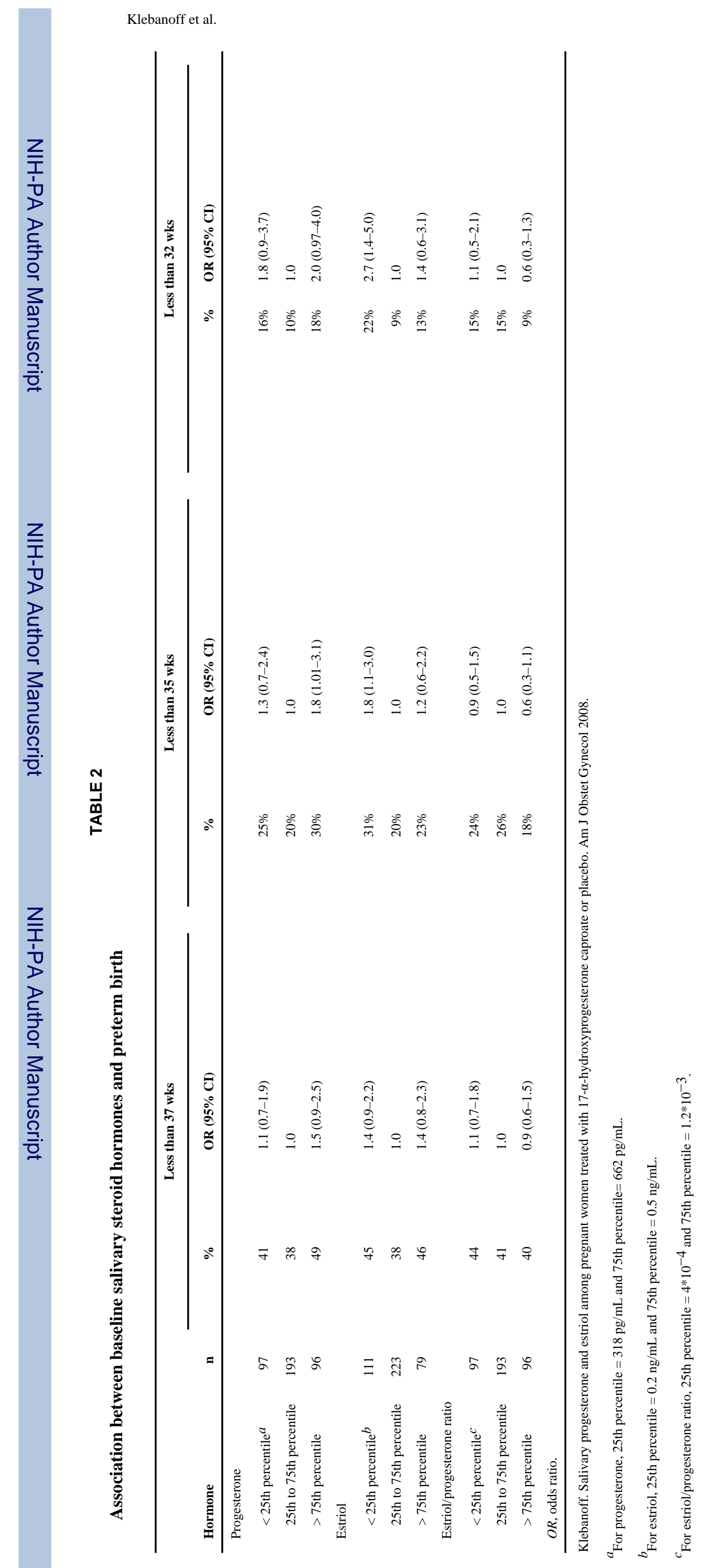

Page 13 